ISA

Arboriculture \& Urban Forestry 2012. 38(5): 171

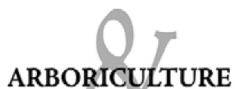

URBAN FORESTRY

Scientific Journal of the

Scientific Journal of the
rnational Society of Arboriculture

\title{
Urban Tree Growth \& Longevity: Introduction
}

This special issue of Arboriculture \& Urban Forestry contains a series of papers related to urban tree growth and longevity. Research and new information on urban tree growth and longevity is important for improved management of our urban trees and forests, as well as assessing their function and value. The papers in this issue were presented at the Urban Tree Growth \& Longevity Conference held on September 12-13, 2011 at The Morton Arboretum (Lisle, Illinois, U.S.). This international conference brought together researchers and practitioners to discuss the current state of knowledge concerning urban tree growth and longevity. The conference covered four topic areas: 1) Descriptive studies of tree growth, longevity, and mortality, 2) Roles of tree production and sales on tree growth and longevity, 3) Roles of site design and tree selection on tree growth and longevity, and 4) Roles of tree and site management on tree growth and longevity. The objectives of the conference and these papers are to: develop collaboration among professionals and researchers to help identify important gaps in our knowledge, foster discussions about promising new methodologies, prioritize research and education needs, and outline a course of action for future research and outreach on urban tree growth and longevity. A few additional papers from the conference will be published in a special section of a future issue of this journal.

E. Gregory McPherson

Research Forester

USDA Forest Service

Bryant C. Scharenbroch

Research Department

The Morton Arboretum 